\title{
Comments from the Expert
}

\author{
Roxana Mehran, ${ }^{1}$ On Behalf of Women as One \\ 1 Department of Cardiology, Icahn School of Medicine at Mount \\ Sinai, Mount Sinai Hospital, New York, United States
}

Ind J Car Dis Wom 2020;5:174

In this unprecedented time of COVID-19, it is imperative to maintain rigorous commitment to developing high quality research which advances our knowledge of the disease mechanisms, impact and treatment options. We know that COVID 19 has affected patient populations differently, and work is ongoing to determine the appropriate care pathways for these distinct groups. As we look more closely at each patient population, taking the impact of the disease on women in particular into account is imperative. Not only for female patients who experience disease differently from a biological standpoint, but also for the women on the front lines. Women make up the majority of healthcare workers world-wide, and are often carrying a disproportionate burden of work at home caring for their families. Assuring

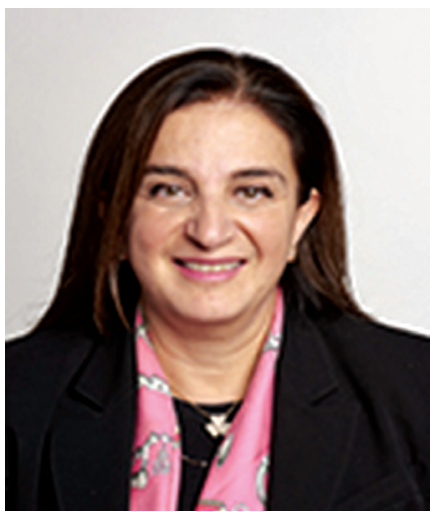
their protection physically, emotionally, and psychologically is essential. The "Consensus Scientific Statement on Advisory Working Guidelines and Recommendations for Female Population in COVID Era by WINCARs" is therefore a necessary manuscript to assure that the worldwide community of healthcare providers is well equipped with the appropriate knowledge to battle this global pandemic successfully.
Address for Correspondence Roxana Mehran, MD, FACC, FACP, FCCP, FESC, FAHA, FSCAI, Department of Cardiology, Icahn School of Medicine at Mount Sinai, Mount Sinai Hospital, 1468 Madison Ave, New York, NY 10029, United States (e-mail: roxana.mehran@ mountsinai.org).
DOI https://doi.org/

10.1055/s-0040-1718610.
(C)2020 Women in Cardiology and Related Sciences
License terms

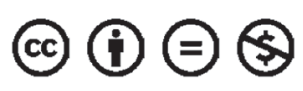

